\title{
Changing Scenario of Language Classrooms in the Present Day World
}

Arun Nepal

\begin{abstract}
The success or failure of language learning and teaching primarily depends upon the activities largely done by teachers and students in classrooms. Moreover, modern educational experts and scholars indicate the need for creating new kind of classroom scenario considering the various factors that differ from one context to another or from one classroom to another. The difference can be in the field of linguistic and cultural background of the students, their needs and interests, and other explicit or implicit areas. This article highlights eight different factors that contribute to creating successful and enjoyable language learning environment addressing the demand of changing scenario of language classrooms in the present day world. Finally, the article justifies the need for new kind of language classrooms providing some crucial evidences.
\end{abstract}

Key words: Classroom, humanistic, success, diversity, enjoyable

\section{Introduction}

A classroom is a combination of many things, including the students and teacher as human being. In addition, the room itself, furniture, board, multimedia, internet and other different materials that decorate the classroom, etc. are the physical things. The management of all these physical features and the arrangement of the furniture in the classroom affect the learning and teaching of language to some extent. The effect of such physical setting is easily noticeable, predictable, explicit and visible - which includes the considerations such as: Whether there is necessary light or not; the furniture are comfortable or not; the room consists of modern technology such as internet, multimedia, etc or not; and so on. However, the activities done by the students and the teachers in the classroom seem subtle, unpredictable, implicit, and largely invisible. The influence of such activities differs from one person to another. My own experience of learning and teaching English also shows that majority of such activities performed by students and teachers are indirect and contextual. The body language and facial expressions of the students and teachers convey different meanings in comparison with the literal meaning of the utterances. Zeichner and Liston (2014) point out that classrooms are fast-paced and unpredictable environments where teachers must make hundreds of spontaneous decisions each day (p. 13).

I have realized the fact that only a little is explicitly known about the activities that possibly happen in the classroom. In line 
with this realization, Van Lier (1988) has quoted the following three sayings of three different scholars to prove the fact that we know very little about what goes on in classroom. One, '...our understanding of classroom and what goes in them is still very limited' (Stenhouse, 1975). Two, '...Our ignorance of what actually happens inside classroom is spectacular' (Stubbs, 1976). Three, '...the ethnography, the society, the social psychology and the educational psychology of the bilingual classroom are all little more than gleams in the eyes of a few researchers' (Fishman, 1977 as quoted in Van Lier, 1988, pp. 77-78). The spirit of all these quotations still exists in many language classrooms even in the present day world. We need to bring about a change in our behaviors in the classroom contemplating the different factors that may play crucial role to make language learning and teaching more effective, enjoyable and successful mainly in the context of Nepal. Hence, the article advocates the need of considering much implicit factors that actually occur inside classrooms. The authentic sources of such factors are the ideas of different scholars and my own English language learning and teaching experience for many years. The claim is that the factors identified through available literature and experience can create an enjoyable atmosphere in the language classroom to make the language learning process more effective, enjoyable and a great success in the days to come. The various factors to be considered in the new kind of language classroom are discussed in the following paragraphs.

\section{Complex Nature of the Classroom}

The physical and explicit nature of the classroom seems very simple. Many of us believe that well-furnished room with modern technologies and multimedia largely facilitates language learning and teaching. Such a class is more comfortable where successful and enjoyable teachinglearning take place. However, such external part of a classroom seems to be secondary. The primary part of a classroom is more implicit and the success or failure of teaching and learning is greatly determined by the behaviors or activities that performed by the students and teacher in the classroom. Such activities empower students in a way that cannotbe predicted easily. Canagarajah (as mentioned in Norton \&Toohey, 2004) argues that classroom discourses and cultures are more complex than we have imagined (p. 135). Such discourse and cultures deserve unpredictable power to bring about a drastic change in the life of students. Osulaand Ideboen (2010) treat classroom as 'the most powerful space on earth'. They claim that the revolutionary objectives of such classroom have the power to transform culture, deepen citizen awareness, and cultivate skills and knowledge whether the classroom is large or small, rich or poor (p.1). Moreover, Dornyei (2001) considers classroom rather as intricate microcosm where students spend a great deal of their life by acquiring skills; learning about the world; making friends; and even falling in love (p. 13). Besides these real life activities, students can be more responsible and autonomous in such classrooms. Dix (2014) advocates creating classrooms where students are keen to accept responsibility and take more control for themselves. He clearly points out the change in traditional classroom scenario where teachers teach and students only listen without taking any responsibility (p. 18). Thus, the nature of the classroom has shifted from the traditional beliefs, norms and values to the modern ones in various ways. Tsui, A. B. M (as mentioned in Carter \& Nunan, 2001) summarizes the extremely complex processes that have been shifted from prescription to description, and from evaluation to awareness raising (Carter \& 
Nunan, 2001, p. 125). The ethnographic research can identify the complex nature and real power of the classroom that sharpens the whole life of the students who can achieve a great success in an enjoyable way in such a modern classroom. Complex nature of whole life of the learners in the classroom can be treated through humanistic perspective as discussed below.

\section{Humanistic Classroom}

Changing scenario of the classroom requires a balanced treatment of students from humanistic perspective. The students are treated as human being in a humanistic classroom. The features of human being like relaxation, encouragement of group dynamics in the class, interpersonal aspects (Thomas 1987); self-esteem (Arnold 1999); ability to speak at least one language, individual differences, different social and cultural background, age (Edge \& Garton 2009); genuine dialogue-discussion, learner's needs, creativity, flexibility (Gowda 2010) are considered largely while teaching in such a classroom.Gowda (2010) argues that humanistic teaching avoids all the manipulative techniques such as rewards, punishments and reinforcements that degrade humans. Instead, he suggests for encouragement and guidance that believe in human dignity and individual freedom (p. 213). Teacher should consider the common humanistic features of all learners found in the classroom. Edge and Garton (2009) describe such features as the learners' names, their knowledge, experience, intelligence, skills, emotions, imagination, awareness, creativity, sense of humor, problems, purposes, dreams, hopes, aspirations, fears, memories, interests, blind spots, prejudices, habits, expectations, likes, dislikes, preferences, ability to speak at least one language and everything else that goes with being a human being (p.3). The balanced treatment of such implicit humanistic features creates an enjoyable atmosphere in the classroom that makes the learners more successful. The treatment of humanistic features creates a social life in the classroom where all the learners enjoy different linguistic and cultural norms, beliefs and other various behaviors that happen in a society.

\section{Social Context in the Classroom}

A classroom is like a small society where the social norms and values can be shared through social like interaction. Creswell (2012) focuses on the studies of single classroom as small societies and subculture groups who share their behavior, beliefs, and language or a combination of all these features (p. 470). Van Lier (1988) further treats classroom as the social context in three senses. One, learning as interactive, hence social activity; two, classroom as a social setting; three, the place of the classroom as one aspect of social life (p.77). In this way, a social context can be created in a classroom where the learners can enjoy social life in a social like setting doing different social activities by sharing their ideas and beliefs in a natural way. The learners participate actively in such activities hoping that they will be successful persons in the future. Expectation of being successful leads them to be more creative and active learners.

\section{Expectation of Success in the Classroom}

Everybody wants to be a successful person in his/her respective field. The desire of being successful is an attribute of human being. Dornyei (2001) argues that 'there is no better recipe for building someone's confidence than to administer regular dosages of success.' He further clarifies that 'success breeds success' (p. 89). Furthermore, Osulaand Ideboen (2010) strongly suggest the teachers to change the 
classroom as 'hope zone' communicating the hope of being success there in. Communicating hope is the springboard to lasting change in the classroom. Such success requires a connection of the students' head and heart. The transformational classroom, where the students are committed to connect their head and heart in a consistent way, leads the students to achieve a great success (pp. 9-156). Such success can be achieved through two-way communication. Lynch (1996) forwards the idea of being flexible in the negotiation of the meaning creating tasks for two-way communication as key to successful language learning practice $(p$. 102). Two-way communication inside the classroom plays vital role to achieve success in language learning and teaching. Stevick (1980, as cited in Arnold, 1999) opines that 'success depends less on materials, techniques, and linguistic analysis, and more on what goes inside and between the people in the classroom' (p. 26). Expectation of being success; communicating hope of being success in the classroom; the connection of head and heart to negotiate meaning for two-way communication among the diverse students; and the activities that happen inside the classroom seem more challenging to address in the classroom where diverse students learn language. The challenge can be addressed only by considering the different backgrounds, levels, needs and interests of diverse students.

\section{Diversity in the Classroom}

As mentioned earlier, a classroom reflects a social setting where all kinds of learners expect to be successful persons in some way. Leung, Harris, and Rampton (1997, as cited in Burns \& Richards, 2009) state that learners bring multiple identities to the classroom (p.43). Similarly, Mani \& Deepthi (2010) indicate that a diverse classroom consists of different kinds of students who may be fast and slow; older or younger; male or female; visual, auditory and kinesthetic; extrovert or introvert; teacher dependent or autonomous; and so on (p. 70). Edge and Garton (2009) further add educational, social, and cultural backgrounds as other diversities in the classroom (p.3). Teacher should be able to take as many advantages as possible from such diversities found in the classroom. Osula and Ideboen (2010) highlight the benefits of diversity in the classroom. They point out that diversity addresses the strengths of each individual; cooperation; positive interaction between cultures, personalities; and individual narratives ( $\mathrm{p}$. 162). Addressing the needs and interests of diverse students naturally leads to create a learning centered classroom where the teachers and the students need to change their traditional roles.

\section{Learning Centered Classroom}

Learning centered classroom is the cry of the day. Active participation of students in an enjoyable way is the basic requirement of such classroom. Mani and Deepthi (2010) point out five different features of learning centered classroom that can contribute a lot to make the learning and teaching process a great success. The first feature focuses on the learning process as an end in itself instead of being the means. The argument is that learning occupies the centre of the teaching-learning process and both teachers and learners concentrate on making the process effective and meaningful. The second belief is that a learning-centered classroom is highly purposeful and goal oriented in which learners know what they are going to learn and they achieve the goal being involved in learning process according to their own abilities, strengths and desires. Different learning styles, multiple intelligences and learner needs replace the traditional mode of content delivery by teachers through 
monotonous lectures. A teacher only provides the learners with opportunities to explore the world around them and learn on their own. Thirdly, a learning centered classroom encourages higher-level thinking skills through a curriculum based on inquiry, critical thinking and problem solving. Such a classroom places a lot of emphasis on activities that involve logical reasoning, discussions, debating, etc. with the objectives of resolving problems or taking decisions. Similarly, involvement of students in peer learning, collaborative work and group tasks is the fourth feature of learning centered classroom. Finally, the evaluation system of learning centered classroom differs from the traditional one. The varied forms of evaluation include written examinations, group presentation, interpretations of drama, films, art, etc. that help learners display their personal strengths and focus on their learning rather than on a finished product in the form of an exam paper (pp. 39-40). A teacher can create an enjoyable learning centered classroom by linking these five features with the class size and the classroom culture that suit the local environment. Lynch (1996) emphasizes that teacher should create interaction opportunities with careful planning and selection of the classroom activity that is appropriate to the class size and more suitable classroom culture with the local environment (p. 68). The emphasis on learning process, learning styles, multiple intelligences, learner needs, critical thinking, reasoning, debating, collaborative work, group presentation, etc. requires devising cognition and metacognition in the classroom.

\section{Cognition and Metacognition in the Classroom}

Cognition and metacognition play crucial role with regard to language learning and teaching. Richards and Schmidt (2010) define the term 'cognition' as 'the various mental processes used in thinking, remembering, perceiving, recognizing, classifying, etc.' (p.90). They also clarify that metacognition refers to knowledge of becoming aware of own mental processes while being involved in different kinds of learning (p. 361). Students need to be engaged in different conscious and subconscious mental activities to develop their unique abilities and intelligences. Unique abilities and intelligences of different individual students in a diverse classroom can achieve the expected success only being involved in different creative works. Such works require much cognitive or mental activities and metacognitive activities in the classroom. Pritchard (2014) suggests creating opportunities for cognitive or mental activity that leads to deeper engagement with ideas and increases the possibility of effective and lasting learning. Deeper understanding is possible through discussion between pair and group works by creating meaningful contexts in the classroom. Furthermore, teacher encourages the students to review and remind the knowledge related to the new topic by scaffolding the thoughtful learners (pp. 35-36). Similarly, Dix (2014) points out the activities that students can do in the metacognitive classroom. He argues that metacognition is at the heart of all learning theory. Metacognitive activities lead teacher and students to think about the way of planning the given learning tasks; negotiate success criteria; monitor comprehension; and evaluate progress ( $\mathrm{p}$. 42). Moreover, Oxford (1990) focuses on both cognitive and metacognitive processes that take place in the classroom. She places the cognitive strategies as more practical activities that involve the students in practicing; receiving and sending messages; analyzing and reasoning; and creating structure for input and output. Similarly, she suggests being involved in different metacognitive strategies that go beyond purely cognitive devices. The metacognitive strategies include centering 
the learning; arranging and planning the learning; and evaluating the learning by the learners themselves (pp. 58-136). Cognitive and metacognitive activities seem more challenging that require much thinking and brainwork on the part of both teacher and students. It seems very difficult to change the habit of the students who have already formed the habit of mechanical learning. Teacher should change the classroom atmosphere where students can do cognitive and metacognitive activities in an enjoyable way lowering their anxiety that generally exists in the diverse classroom.

\section{Anxiety Free and Enjoyable Classroom}

Active participation of students in different cognitive and metacognitive interactions requires low classroom anxiety or an anxiety free and enjoyable classroom environment. Richards and Rodgers (2001) argue that low personal anxiety and low classroom anxiety are more conducive to second language acquisition (p.183). Similarly, Brown (1987) suggests creating anxiety free classroom environment by involving the students in singing; laughing with them; sharing their fears in small groups; promoting cooperative learning among students; getting them to set their own goals beyond the classroom goals; and so on (pp. 128-131). Such anxiety free environment requires an active participation of the students in the classroom.Dornyei (2001) suggests a way of enjoyable learning through creation of classroom situations where students become active participants. Students usually enjoy a task if they play an essential part in it (p. 77). Teacher can create an effective and enjoyable atmosphere in the classroom in different ways. Oxford (1990) suggests three different ways to make the class more effective and enjoyable. The first way is to change the social structure of the classroom to give students more responsibility. Secondly, it is necessary to provide the increased amount of naturalistic communication. Finally, learners use affective strategies such as lowering anxiety, taking emotional temperature and encouraging themselves for learning (pp. 140-141). Dornyei (2001) suggests reducing the fear of social comparison, competition, mistakes, and tests while turning the language classroom into 'anxiety free zone' (pp.92-94). The anxiety free and enjoyable classroom where diverse students participate actively in different cognitive and metacognitive activities to gain expected success and other factors discussed above clearly indicate the need for changing the existing scenario of the language classroom in the present day world.

\section{Need for Changing Classroom}

The factors mentioned in the preceding paragraphs clearly indicate the need for new kind of classroom where the students can learn in an enjoyable way to achieve the expected success. Such success requires conducive classroom setting where all students are treated considering the complex nature of the classroom as mentioned above. Duncan (as cited in Zeichner and Liston, 2014,) argues in favour of bringing varieties in the classroom that is beyond a 'one-size-fits all' model (p.82). A shift from such a model has become necessary in the modern classrooms. Dornyei (2001) emphasizes the shift from more examination-oriented, monotonous and boring classroom setting to more process-oriented and enjoyable classroom where students get involved actively (p. 72). Dornyei and Murphey (2003) further suggest bringing about change in the traditional classroom setting by changing the partners as necessary; changing the seating arrangements; maintaining the classroom temperature and lighting; decorating the classroom; 
using songs and music in the classroom; and giving the sense of ownership in the classroom (p. 89). The sense of ownership creates a safe and secure environment where students can take part in different communicative activities without any hesitation like in the natural setting. Ellis (2008) points out the need for an ideal communicative classroom that leads to successful L2 learning. Such setting examines the key theoretical issues in specific classroom contexts that promote L2 acquisition in a natural way (pp. 824-825). This short discussion provides some crucial evidences to the urgent need of changing the existing classroom scenario.

\section{Conclusion}

This article is the result of the need and realization of the new kind of classroom setting in the present day world that differs from traditional forms of the classroom (primarily the 'one-size-fits all' models). The realization is to bring about a drastic change in the traditional classroom setting considering the various factors that were less emphasized in the past. An enjoyable and successful language learning and teaching depend largely on the various factors that are still known little. The article is an attempt to search the implicit factors that play very indirect and crucial role to address the complex nature of the classroom.

The complex nature of classroom requires treating the students from humanistic perspective. Natural characteristics of human being should highly be respected in the language classrooms. People enjoy different kinds of activities in the society according to their need, interest, and desire that have close relationship of being successful persons in their real life. The expectation of success in diverse students requires much learner-centered classroom where different cognitive and metacognitive activities take place. Students can enjoy being involved in such cognitive and metacognitive activities only in anxiety free classroom setting where they can communicate freely. Creating an anxiety free, enjoyable and natural-like communication atmosphere indicates the need for new kind of classroom.

The changing scenario of the language classroom can address the universal desire of human being to become successful in an enjoyable way to gain internal satisfaction. The new kind of classroom is expected to give such internal satisfaction to both students and teachers that is possibly an ultimate objective of almost all people. The students will be internally satisfied if they can achieve expected success in language learning and the teachers will gain such satisfaction if they find their teaching more effective and successful. Hence, the changing scenario of the classroom places primary emphasis on the behaviors and the activities of both students and teachers that take place in the classroom. The claim of this article is that if the students and teachers become ready to apply the above mentioned factors and the like in their practical life, the deteriorating condition of learning and teaching will be improved in a dramatic way.

\section{References}

Arnold, J. (Ed.). (1999). Affect in language learning. Cambridge: Cambridge University Press.

Brown, H.D. (1987). Principles of language learning and teaching ( $\left.3^{\text {rd }} \mathrm{Ed}\right)$. Englewood Cliffs, CA:Prentice Hall Regents.

Burns, A. and Richards, J.C. (Eds.). (2009). The Cambridge guide to second language teachereducation. New York: Cambridge University Press. 
Carter, R. and Nunan, D. (Eds.). (2001). The Cambridge guide to teaching English to speakers of other languages. UK: Cambridge University Press.

Cresswell, J.W. (2012). Educational research (4 ${ }^{\text {th }}$ Ed.). New Delhi: PHI Learning Private Limited.

Dix, P. (2014). The essential guide to classroom assessment. UK: Pearson.

Dornyei, Z. (2001). Motivational strategies in the classroom. New York: Cambridge University Press.

Dornyei, Z. and Murphy, T. (2003). Group dynamics in the language classroom. New York: Cambridge University Press.

Edge, J and Garton, S. (2009). From experience to knowledge in ELT. UK: Oxford University Press.

Ellis, R. (2008). The study of second language acquisition $\left(2^{\text {nd }} \mathrm{Ed}\right)$. New York: Oxford University Press.

Gowda, M.S. (2010). Learning and the learner: Insight into the processes of learning and teaching. New Delhi: PHI Learning Private Limited.

Lynch, T. (1996). Communication in the classroom. New York: Oxford University Press.

Mani, P. and Deepthi, S. (2010). English for teaching for secondary school teachers. New York: Cambridge University Press.

Norton, B. and Toohey, K. (Eds.). (2004). Critical pedagogies and language learning. New York: Cambridge University Press.

Osula, B and Ideboen, R. (2010). 10 winning strategies for leaders in the classroom: a transformational approach. New Delhi: SAGE.

Oxford, R.L. (1990). Language learning strategies: What every teacher should know. Boston:Heinle\&Heinle Publishers.

Pritchard, A. (2014). Ways of learning: Learning theories and learning styles in the classroom. ( ${ }^{\text {rd }}$ Ed.). London \& New York: Routledge.

Richards, J.C. and Rodegers, T.S. (2001). Approaches and methods in language teaching (2nd Ed.). United Kingdom: Cambridge University Press.

Richards, J.C. and Schmidt, R. (2010). Longman dictionary of language teaching and applied linguistics (4th Ed.). Great Britain: Pearson Education Limited.

Thomas, A.N. (1987). Classroom interaction. New York: Oxford University Press.

Van Lier, L. (1988). The classroom and the language learner. London and New York: Longman.

Zeichner, K.M. and Liston, D.P. (2014). Reflective teaching: An introduction ( $2^{\text {nd }}$ Ed.). New York: Routledge.

\section{Author's bio}

Arun Nepal, M.Ed. in English, is a Lecturer at Tribhuvan University. His research interests include ELT methodology, language learning strategies, and reflective practice. Currently he is a PhD scholar exploring learning strategies. 